The use of morphine is mentioned in nine cases by various reporters, two of these cases proving fatal.

Eight cases were bled, three proving fatal. One of these latter was a case of my own, where the patient was promptly delivered, but where the convulsions continued for two days post-partum until her death, notwithstanding every means that could be employed. Here venesection gave temporary relief. Copious bleeding, followed by intravenous salt-solution injec. tions, would seem to promise good results.

'The use of verutrum viride, as recommended by many practitioners in the South and West, is not mentioned in this collection of cases.

\section{Clinital यूDepartment.}

\section{A CASE OF BULLE'T-WOUND OF 'FHE HEAD.}

$$
\text { "Y A. T. CABOT, A.M. M.D., BOS'TON. }
$$

C. H., fifty-five years of age, entered the Massachusetts Generai Hospital on October 25, 1892. 'Twenty hours before entrance he had shot himself in the left side of the head with a revolver, the bullet, of 32 . calibre, entering just above the left temporal bone. He was a Swede, and talked but little English, but would unswer "Yes" or "No" to simple questions.

An examination showed the characteristic wound of eutrance of a bullet of the described size. 'This opening was situated one and a half inches above a line drawn from the externul orbital process to the junction of the helix of the ear to the scalp, and was nearly over the centre of this line, being slightly nearer to the ear than to the orbital process. His eyes were moderately contracted, but reacted equally to light. At the time of entrance his temperature was $101.4^{\circ}$; his pulse was 90 , his respiration 36 . He was seen soou after by Dr. J. J. Putuam, who made the following notes:

"The patient shows complete paralysis of the lower brauches of the facial nerve, and difficulty in the movements of the tonguc, also complete paralysis of the right hand and arm. Neitber leg is wholly paralyzed, but both are equally weak. The knee-jerk is slight, but present at both sides. $\mathrm{He}$ is sensible to a prick everywhere. He seems to understand simple questions, and is apparently intelligent, but is evidently aphasic. His pulse is 84 , respirations 27 . He can swallow."

Dr. Putuam's opinion was that the lower Rolandic region, which lay close to the wound, was evidently seriously injured. How much further the damage extended could not be determined on account of the condition of general concussion. It was decided to operate with the object, primarily, of estublishing drainage.

Aiter thoroughly shaving and cleansing the head, the scalp was reflected and a trephine opening was made over the point of entrance of the bullet. A probe was then introduced through the opening in the dura mater, and, with the head turned on the side, was allowed to run by its own weight along the track of the ball. It slipped along easily until it encountered the falx, where it stopped abruptly, but a little gentle manipulation carried it through the opening and it then ran, by its own weight, directly across to the skull on the other side. By taking a probe long enough to project considerubly from the skull, while it lay in the bullet track, it was possible to sight pretty accurately the course of the ball. It was thus found that it had traversed the brain from side to side with an inclination backward; so that it must have struck the inside of the skull, on the other side, under the posterior part of the parietal eminence.

The probable point being determined by careful observation of the probe, a needle was thrust through the scalp, and, reflecting a flap, a trephine was put on; and when the button of the bone was removed, it was found that the probe from the other side touched the dura at the centre of the opening.

An incision was made in the dura, which had not been lacerated by the bullet. At once clots of blood and brain matter began to issue, and a probe, feeling about with great gentleness, denonstrated a cavity in the brain substauce posterior to the opening. The finger was carefully introduced into this; the bullet was felt and, with a little difficulty, was seized and removed.

A drainage-tube was introduced into the cavity where the bullet had lain, and another small one was slipped just within the wound of entrance.

'The patient gradually failed, and died twenty-four hours after the operation.

The interesting point in this case is that the method adopted succeeded in 80 accurately locating the point of the probe on the opposite side of the head. The probe was sighted while looking at the head first from the top and then from the side, and in each position a line was drawn passing around the head in the same plane with the probe and the eye. 'The point of intersection of these lines on the opposite side gave the position of the distal end of the probe. Fortunately, the bullet had not ricocheted after striking the inner surface of the skull, and was found close to the point of impact.

Patients often recover with an injury of the brain as extensive as seemed to exist in this case; and it would seem possible that had this patient come to operation earlier, the result might have been more fuvorable.

\section{A BULLE'T-WOUND OF 'THE BRAIN.}

BY DAVID DANA BlEAR, A.M., M.D., FHENPOK', ME.

ON December 30, 1896, a little child, twenty-one months old, was accidentally shot with a bullet from a .22-inch calibre revolver. The missile entered the head on the posterior left side about midway between the upper part of the left ear and the occipital protuber. ance. The direction of the line of entrance was diagonal. 'There was no wound of exit. Matted hair, looped, two and one-half inches in length, was taken from the wound; so that it must have been of at least that depth, and how much more is unknown. The wound was not probed.

Immediately ufter the shot the child fell to the floor, apparently dead; but after a few moments began to breathe irregularly. An hour later she was seen by the writer. The condition was one of severe shock and concussion; both pupils were contracted to a small point and were inclined to roll upward.

'I'wo-hours later she was seen by Dr. 'Twitchell, of Portlund, who concurred that the wound should not be probed to find the bullet. The condition of concus- 
sion lasted about five days, when consciousness gradually returned, and at the present writing the child is apparently as well as at uny time in her short life. There is 110 paralysis, no change of vision, no fever; since the fifth day of the accident, no vomiting.

The treatment of the wound was antiseptic until healing had taken place. The bullet is still in the brain, and gives no symptoms.

\section{Reportw af Sacietieg.}

\section{THE OBSTE'TRICAL SOCIETY OF BOSTON.}

(IIARLKG W. TOWNAKNI), M.D., SECRITARY.

Rligulan Meeting December 15, 1896, the President, Dr. Jarlis R. Ciradwick, in the chair.

Dr. Alfred Worcestikr reported

FIVE CASES OF ECLAMPIA, WITH COMMENTS UPON THE TREATMENT. ${ }^{2}$

Dr. Charles W. Townslind read a paper on I'UERIERAL ECLAMPSIA,"

which was a study of 160 cases occurring at the Boston Lying-in Hospital and in the private practice of nembers of the Obstetrical Society of Boston.

Dr. A. D. Sinclaik said he could not agree with Dr. Worcester that manual dilatation and version was poor treatment in eclampsia. It is of great importance to fully dilate the cervix before attempting to extract. Cases of eclampsia differ very much in severity; some will get well, and some will dic in spite of treatment, but he knew of no one remedy so successful as manual dilatation and version.

DR. J. P. REYNoLDs had never seen any harm from the prolonged and continuous use of ether, neither had he seen any recurrence of the convulsions after its persistent use.

DR. F. B. HA RRINGTON remarked that the diminished urine in these cuses was probably a symptom of the general toxemia, and not a cause.

Dir. J. G. Bl.akn suid that his own course of action was to give ether and empty the uterus at once, and that he relied on the record of five successful cases to bear lim out in this belief. In two others that had come under his observation where other methods were first used the patients were lost.

Dr. Grorgk Haven said the whole subject was shrouled in mystery, and there is much yet to be learned about the pathology and proper treatment of the affection. On theoretical grounds he would prefer chloroform to ether in these cases, ulthough he had not used it. In some cases hot-air baths will not produce sweating and pilocarpine will.

Dr. Dol.l.IVER stated that 'Tarnier had reduced the mortulity from eclampsia in recent years in his clinic to nine per cent. by means of a milk diet.

1)R. linglimann believed if we bleed we must do so freely, and if we use morphine we must give large doses. He had always used chloroform, never having used ether or pilocarpine. He had placed some reliance on calomel. He believed in delivery as soou as possible, in venesection and in large initial doses of morphine. Ho believes that the ideal treatment would

\footnotetext{
1 Seo page 204 of tho Journal.
}

2 Soo page 205 of the Journal. be venesection with intra-venous injections of salt solution, thus ridding the system of toxins. He referred to a recent report of 31 cases in Geneva, four of which had icterus of which three died, showing that the liver as well as the kidneys is affected by the toxemia.

Dr. J. 13. Swift said he would like to ask what constituted the rationale of immediate delivery. If the child has not reached a viable age, why sacrifice it? It would seem as if wo should devote ourselves to the elimination of the poison.

Dr. A. 1). Sincralr said that early statistics give a mortality of 50 per cent. in eclaupsia. It is about one-half that now, the improvement being due, he thought, to anesthesia, rapid delivery and the use of prophylactic trentment.

Dr. C. M. Greis said he had seen a large number of cases at the Boston Lying-in Hospital and in consultation practice, but had never had a case in his own practice, although he laas, he thinks, prevented a number by prophylactic measures. The most important thing in the exumination of the urine is the amount of urea, not of albumin. He has recently had a cuse where there were headaches, epigastric pain, edema and albuminuria, but under prophylactic treatment no eclampsia resulted. 'The pathology of the affection is still obscure. In one autopsy made by Dr. Councilman there was found to be general pneumococcus infection of the liver, lunges and all the orgins.

He believes in the delivery of the eclamptic patient, experience showing that that gives the best results. He referred to a case where marked edema occurred in the latter part of pregnancy. In spite of most careful prophylactic treatment the patient had convulsions. She was at once delivered, and had no more; and a year later her urine was normal. He does not look on pilocarpine as such a dangerous drug as sonse think, and he uses it where hot batlis do not work. Hotwater baths are excellent, being far better than the hot-air baths for inducing perspiration, but they are more difficult to manage. The patient should bo kept in the bath till the forehead is covered with perspiration.

Dr. W. E. Boariman said that manual dilatation and delivery was used in the earlier part of the century by Ashwell and Michael Regan. It was given up, but we have again returned to it.

Dr. A. Worces'rer said that in eclampsia the common practice is to absolutely disregard the life of the child. He would urgently recommend the practice of prophylactic treatosent in all cases indicating approaching eclampsia, and of all symptoms the diminution or suspension of urine is most important. He believes that ether does no good; he has lost four cases where full etherization was employed.

Dr. C. W. 'Townsend, in closing, referred to the great variation as to mortality in cases of eclampsia. Some of those that are apparently most hopeless recover, while others that are seen early and appear to be most promising, die. Ho read the following reports of post-mortem examinations recently made by Dr. J. H. Wright on cases of eclampsia dying at the hospital.

Synopsis of Autopsy upon H. K. - Body that of a young well.developed woman, showing evidence of recent pregnancy. The chief lesions were as follows:

Liver. Pale, yellowisl, opaque, showed some punctate hemorrhages in capsule. 'The microscopic examination 